\title{
Analisis Kebutuhan Sumur Resapan Sebagai Salah Satu Upaya Dalam Mereduksi Banjir Genangan
}

\author{
Meliyana $^{1}$, Ichsan Syahputra ${ }^{1}$, Helwiyah Zain ${ }^{1}$, Antoniadi Zal ${ }^{1}$ \\ ${ }^{1}$ Program Studi Teknik Sipil, Fakultas Teknik, Universitas Abulyatama, Jl. Blang Bintang \\ Lama Km 8,5 Lampoh Keude Aceh Besar, 23372, Indonesia \\ *Email korespondensi : meliyana_sipil@abulyatama.ac.id
}

Diterima 21 Mei 2018; Disetujui 7 Juli 2018; Dipublikasi 31 Juli 2018

\begin{abstract}
Impermeable land in a region can not absorb rain water, so that rain water becomes run off and cause flood inundation. Absorption wells function to accommodate and absorb rain water into the soil. The purpose of this study to know the value of soil permeability, determine the dimensions and number of absorption wells in reducing flood. The study was conducted at Elementary School 1 Pulo Ie Kabupaten Nagan Raya with area of $1500 \mathrm{~m}^{2}$ and the number of buildings as many as 4 units. The absorption well planning refers to regulation of the Minister of Public Works 11/PRT/M/2014. The data used in the planning form average daily rainfall, flood volume, soil permeability value, runoff coefficient value, depth of ground water level and wide field of cistern. The result of analysis obtained maximum daily rainfall average maximum $(R)$ equal to $36,25 \mathrm{~mm} /$ day, volumes of flood $\left(V_{a b}\right) 11,552 \mathrm{~m}^{3}$, cistern area $497 \mathrm{~m}^{2}$, runoff coefficient value of 0.75 and soil permeability value $(K)$ $0.009725 \mathrm{~cm} / \mathrm{sec}$ or $8.40 \mathrm{~m} /$ day. Rectangular Absorption wells with depth of well $(H) 1.60$ meters and base well $(L)$ width 1.20 meters. The number of absorption wells required 5 units. Thus, the flood of inundation at the Elementary School 1 Pulo Ie can be accommodated by the absorption wells, so that the flood of inundation can be overcome.
\end{abstract}

Keywords : Absorption wells, flooding inundation, soil permeability

\begin{abstract}
Abstrak: Lahan tertutup atau kedap air pada suatu kawasan tidak bisa meresapkan air hujan yang turun, sehingga air hujan menjadi limpasan permukaan (run off) dan menyebabkan banjir genangan. Sumur resapan berfungsi menampung dan menyerapkan air hujan ke dalam tanah. Tujuan dari penelitian ini untuk mengetahui nilai permeabilitas tanah, menentukan dimensi dan jumlah sumur resapan dalam mereduksi banjir genangan. Penelitian dilaksanakan di Sekolah Dasar Negeri 1 Pulo Ie Kabupaten Nagan Raya dengan luas area $1500 \mathrm{~m}^{2}$ dan jumlah bangunan sebanyak 4 unit. Perencanaan sumur resapan mengacu pada Peraturan Menteri Pekerjaan Umum 11/PRT/M/2014. Data yang digunakan dalam perencanaan berupa curah hujan harian rata-rata, volume banjir, nilai permeabilitas tanah, nilai koefisien limpasan permukaan, kedalaman muka air tanah dan luas bidang tadah. Hasil analisis diperoleh tinggi curah hujan harian rata-rata maksimum (R) sebesar $36,25 \mathrm{~mm} / \mathrm{hari}$, volume andil banjir $\left(\mathrm{V}_{\mathrm{ab}}\right)$ sebesar $11,552 \mathrm{~m}^{3}$, luas bidang tadah sebesar $497 \mathrm{~m}^{2}$, nilai koefisien limpasan $(\mathrm{C})$ sebesar 0,75 dan nilai permeabilitas tanah $(\mathrm{K}) 0,009725 \mathrm{~cm} /$ detik atau $8,40 \mathrm{~m} / \mathrm{hari}$. Sumur resapan penampang segiempat dengan kedalaman sumur (H) 1,60 meter dan lebar alas sumur (L) 1,20 meter. Jumlah sumur resapan dibutuhkan 5 unit. Maka, banjir genangan pada Sekolah Dasar Negeri 1 Pulo Ie dapat ditampung seluruhnya oleh sumur resapan, sehingga banjir genangan dapat diatasi.
\end{abstract}

Kata kunci : sumur resapan,banjir genangan, permeabilitas tanah 
Salah satu permasalahan utama yang dihadapi sebagian wilayah di Indonesia pada musim hujan sering terjadi permasalahan banjir. Terjadinya perubahan tutupan lahan menyebabkan sebagian besar air hujan yang jatuh kepermukaan tanah sulit meresap ke dalam tanah dan akhirnya menjadi limpasan (run off) dan dapat menyebabkan terjadinya banjir.

Berdasarkan Peraturan Menteri Pekerjaan Umum Nomor 11 Tahun 2014, pengelolaan air hujan pada bangunan gedung adalah upaya dan kegiatan untuk mempertahankan kondisi hidrologi alami, dengan cara memaksimalkan pemanfaatan air hujan, infiltrasi air hujan, dan menyimpan sementara air hujan untuk menurunkan debit banjir melalui optimasi pemanfaatan elemen alam dan pemanfaatan elemen buatan. Salah satu pemanfaatan elemen buatan berupa pembuatan sumur resapan.

Kusnaedi (2011) menyatakan bahwa sumur resapan resapan berfungsi sebagai tempat menampung air hujan yang jatuh di atas atap rumah atau daerah kedap air dan meresapkannya kedalam tanah sehingga memiliki waktu tinggal dipermukaan tanah lebih lama, sedikit demi sedikit air dapat meresap ke dalam tanah.

Lokasi studi kasus di Sekolah Dasar Negeri 1 Pulo Ie yang terletak di Kecamatan Kuala Kabupaten Nagan Raya. Luas area $1500 \mathrm{~m}^{2}$ dengan jumlah bangunan sebanyak 4 unit, ketinggian banjir genangan 10 - $20 \mathrm{~cm}$ dan lama genangan 4 sampai 6 jam. Tujuan dari penelitian ini adalah untuk mengetahui nilai permeabilitas tanah, menentukan dimensi dan jumlah sumur resapan dalam mereduksi banjir genangan.

\section{KAJIAN PUSTAKA}

Kajian pustaka ini diuraikan berbagai literatur berisikan teori-teori yang berkaitan dengan judul penelitian yang akan dibahas.

\section{Sumur Resapan Secara Umum}

Sumur resapan merupakan sumur atau lubang pada permukaan tanah yang digunakan untuk menampung air hujan agar dapat meresap kedalam tanah dan kembali ke siklus air yang semestinya, sehingga air tidak menggenang dipermukaan tanah dan menyebabkan banjir (Kusnaedi, 2011).

Dalam Peraturan Menteri Lingkungan Hidup Nomor 12 Tahun 2009, bahwa upaya pembangunan sumur resapan air hujan juga merupakan teknik konservasi air yang pada hakikatnya adalah upaya manusia dalam mempertahankan, meningkatkan, dan mengembangkan daya guna air sesuai dengan peruntukannya dan dapat dicapai dengan memperbesar tampungan air tanah, memperkecil dimensi jaringan drainase, mempertahankan elevasi muka air tanah, mencegah intrusi air laut untuk daerah pantai, dan memperkecil pencemaran air tanah.

Dalam perencanaan sumur resapan, karakteristik tanah merupakan hal yang sangat penting diperhatikan, tekstur tanah berpasir memiliki karakteristik dapat meresapkan air dengan cepat (Suripin, 2004)

Berdasarkan Peraturan Menteri Pekerjaan Umum Nomor 11 Tahun 2014, persyaratan prosedur evaluasi lokasi sumur resapan yang harus dipenuhi antara lain: 
a. Kedalaman air tanah minimum 1,50 meter pada musim hujan dan minimum 3 meter pada musim kemarau;

b. Struktur tanah yang dapat digunakan harus mempunyai nilai permeabilitas tanah lebih besar dari 2,00 cm/jam;

c. Jarak penempatan sumur resapan air hujan terhadap bangunan.

\section{Tabel.1 Jarak sumur terhadap bangunan}

\begin{tabular}{clc}
\hline No & Jenis bangunan & Jarak minimum $(\mathrm{m})$ \\
\hline 1 & Sumur air bersih & 3 \\
2 & Pondasi bangunan & 1 \\
3 & Tangki septik & 5 \\
\hline
\end{tabular}

\section{Konstruksi Sumur Resapan}

Bentuk bangunan sumur resapan dapat dibuat segiempat atau silinder dengan kedalaman tertentu dan dasar sumur terletak diatas permukaan tanah.

Beberapa tipe dan konstruksi sumur resapan air hujan dan peruntukannya (Peraturan Menteri Pekerjaan Umum Nomor 11 Tahun 2014) sebagai berikut:

a. Sumur resapan tipe I

Tipe sumur resapan ini dengan dinding tanah diterapkan pada tanah geluh kelanauan dan diterapkan pada kedalaman maksimum 3 meter.

b. Sumur resapan tipe II

Dengan dinding pasangan batako atau bata merah tanpa diplester, dan diantara pasangannya diberi lubang. Tipe ini diterapkan pada kedalaman tanah maksimum 3 meter, untuk semua jenis tanah.

c. Sumur resapan tipe III

Dengan dinding buis beton porous atau tidak porous, pada ujung pertemuan sambungannya diberi celah lubang. Tipe ini diterapkan pada kedalaman maksimum sampai dengan permukaan air tanah.

d. Sumur resapan tipe IV

Dengan dinding buis beton berlubang. Tipe ini diterapkan pada kedalaman maksimum sampai dengan permukaan air tanah.

Peraturan Menteri Pekerjaan Umum Nomor 11 Tahun 2014 menetapkan data teknis sumur resapan air sebagai berikut:

a. Ukuran minimum diameter 1,00 meter.

b. Ukuran pipa masuk diameter $110 \mathrm{~mm}$.

c. Ukuran pipa pelimpah diameter $110 \mathrm{~mm}$.

d. Ukuran kedalaman 1,5 sampai dengan $3 \mathrm{~m}$.

e. Dinding dibuat dari pasangan bata atau batako dari campuran 1 semen : 2 pasir : 3 kerikil pasir tanpa plester.

f. Rongga sumur resapan diisi dengan batu kosong 20/20 setebal $20-40 \mathrm{~cm}$.

g. Penutup sumur resapan dari plat beton tebal 10 $\mathrm{cm}$ dengan campuran 1 semen : 2 pasir : 3 kerikil.

\section{Koefisien Permeabilitas Tanah}

Permeabilitas adalah kemampuan tanah untuk meloloskan atau meresapkan air ke dalam tanah. Untuk menentukan koefisien permeabilitas di laboratorium dapat dilakukan dengan (Braja M.Das,1998):

$$
K=2,303 \frac{a \cdot(L s)}{A s .(t)} \log \frac{h_{1}}{h_{2}}
$$

Keterangan:

$\mathrm{K}=$ Koefisien permeabilitas tanah ( $\mathrm{cm} /$ detik)

$\mathrm{a}=$ Luas penampang pipa $\left(\mathrm{cm}^{2}\right)$

$\mathrm{T}=$ Interval penurunan $\mathrm{h}_{1} \mathrm{ke}$ (detik) 


$$
\begin{aligned}
\mathrm{h}_{1}= & \text { Ketinggian mula-mula air pada interval } \\
& \text { waktu tertentu }(\mathrm{cm}) \\
\mathrm{h}_{2}= & \text { Ketinggian akhir air pada interval waktu } \\
& \text { tertentu }(\mathrm{cm})
\end{aligned}
$$

\section{Kedalaman Muka Air Tanah}

Kedalaman muka air tanah harus $\geq 3$ meter pada musim kemarau dan $\geq 1,5$ meter muka air tanah pada musim hujan, menurut peraturan persyaratan pembuatan sumur resapan jika kurang dari persyaratan yang telah ditetapkan maka disarankan untuk dibuat sistem penampungan air terpusat seperti waduk, embung, dan lain-lain (Permen PU No 11/ PRT/M/2014).

\section{Analisis Hidrologi}

Analisis hidrologi sangat diperlukan dalam suatu perencanaan sumur resapan untuk dapat menentukan besarnya dimensi sumur resapan yang akan dibangun.

- Cara rata-rata Aljabar

Metode ini hanya disarankan digunakan untuk wilayah yang relatif rata atau datar, harga individual curah hujan tidak terlalu jauh dari harga rata-ratanya (Soewarno, 1995).

Adapun rumus perhitungan metode Aljabar adalah sebagai berikut:

$$
R=\frac{(R 1+\mathrm{R} 2+\ldots+\mathrm{Rn})}{n}
$$

\section{Keterangan:}

$\mathrm{R}=$ Curah hujan rata-rata $(\mathrm{mm})$

$\mathrm{n}=$ Jumlah tahun (data)

$\mathrm{Rn}=$ Banyak tinggi curah hujan harian
○ Volume Andil Banjir

Volume andil banjir adalah debit air hujan yang jatuh ke bidang tadah. Rumus yang digunakan berdasarkan Peraturan Menteri Pekerjaan Umum No.11 Tahun 2014:

$$
V_{a b}=0,855 \cdot C_{\text {tadah }} \cdot A_{\text {tadah }} \cdot R
$$

\section{Keterangan:}

$\mathrm{V}_{\mathrm{ab}} \quad=$ Volume andil banjir $\left(\mathrm{m}^{3}\right)$

$\mathrm{C}_{\text {Tadah }}=$ Koefisien limpasan bidang tadah

$\mathrm{A}_{\text {Tadah }}=$ Luas bidang tadah $\left(\mathrm{m}^{2}\right)$

$\mathrm{R}=$ Tinggi hujan harian tahunan ratarata maksimum (mm)

\section{Analisis Sumur Resapan}

Perhitungan sumur resapan air hujan sesuai dengan Peraturan Menteri Pekerjaan Umum Nomor 11/PRT/M/2014.

a) Volume air hujan yang meresap

Digunakan rumus berikut:

$$
\begin{aligned}
& V_{r s p}=\frac{t_{e}}{24} \cdot A_{\text {total }} \cdot K_{\text {rata-rata }} \\
& t_{e}=0,9 \cdot R^{0,92} / 60 \\
& K_{\text {rata-rata }}=\frac{k_{v} \cdot A_{h}+k_{h} \cdot A_{v}}{A_{h}+A_{v}} \\
& A_{\text {total }}=\left(A_{\mathrm{v}}+A_{h}\right)
\end{aligned}
$$

Keterangan:

$\mathrm{V}_{\text {rsp }}=$ Volume air hujan meresap $\left(\mathrm{m}^{3}\right)$

te $\quad=$ Durasi hujan efektif (jam)

$\mathrm{A}_{\text {total }}=$ Luas dinding sumur + luas alas sumur $\left(\mathrm{m}^{2}\right)$

$A_{h}=$ Luas alas sumur dengan penampang segiempat $=$ P.L $\left(\mathrm{m}^{2}\right)$

$\mathrm{A}_{\mathrm{v}} \quad=$ Luas dinding sumur dengan penampang segiempat $=4 . \mathrm{H} \cdot \mathrm{L}\left(\mathrm{m}^{2}\right)$

$\mathrm{R}$ = Tinggi hujan harian rata-rata $(\mathrm{mm})$

$\mathrm{K}=$ Permeabilitas tanah (m/hari) 
b) Volume penampungan (storasi) air hujan

Perhitungan volume penampungan

digunakan rumus sebagai berikut:

$$
V_{\text {storasi }}=V_{a b}-V_{r s p}
$$

c) Penentuan jumlah sumur resapan air hujan

Penentuan jumlah sumur resapan air hujan, dengan rumus sebagai berikut:

$$
\begin{aligned}
& H_{\text {total }}=\frac{V_{\text {storasi }}}{A_{h}} \\
& n=\frac{H_{\text {total }}}{H_{\text {rencana }}}
\end{aligned}
$$

\section{Keterangan:}

$\mathrm{H}_{\text {total }} \quad=$ Kedalaman total sumur resapan air hujan (m)

$\mathrm{V}_{\mathrm{ab}} \quad=$ Volume andil banjir $\left(\mathrm{m}^{3}\right)$

$\mathrm{V}_{\text {Isp }} \quad=$ Volume air hujan meresap $\left(\mathrm{m}^{3}\right)$

$\mathrm{A}_{\mathrm{h}} \quad=$ Luas alas sumur dengan penampang segiempat $=\mathrm{H} . \mathrm{L}\left(\mathrm{m}^{2}\right)$

$\mathrm{n}=$ Jumlah sumur resapan (unit)

$\mathrm{H}_{\text {rencana }} \quad=$ Kedalaman yang direncanakan $<$ kedalaman air tanah (m)

\section{METODOLOGI PENELITIAN}

Penelitian dilakukan pada kawasan Sekolah Dasar Negeri 1 Pulo Ie Kecamatan Kuala, Kabupaten Nagan Raya. Letak geografis pada koordinat 4०05'29.2" lintang utara dan 96 16'39.4" bujur timur. Luas area $1500 \mathrm{~m}^{2}$ dengan jumlah bangunan sebanyak 4 unit.

Rencana metodologi meliputi analisa hidrologi, analisis sumur resapan dan pengumpulan data analisa data. Pengumpulan data yang dilakukan berupa pengumpulan data curah hujan 10 tahun terakhir, pengukuran kedalaman muka air tanah, pengukuran luas bidang tadah, pengambilan sampel tanah.

Penentuan besaran nilai koefisien permeabilitas $(\mathrm{K})$ dilakukan dengan pengujian
Falling Head Permeability Test di laboratorium UPT Universitas Syiah Kuala. Analisis hidrologi meliputi perhitungan curah hujan rata-rata harian dihitung menggunakan metode rata-rata Aljabar dan volume andil banjir.

Analisis sumur resapan meliputi, perhitungan volume air hujan meresap, volume penampungan dan penentuan jumlah sumur resapan.

\section{HASIL PEMBAHASAN}

\section{Kondisi Eksisting Muka Air Tanah}

Sumur air bersih yang diukur sebagai sampel sebanyak 3 unit yaitu, sumur air bersih I memiliki kedalaman muka air tanah mencapai 1,65 meter, sumur air bersih II sebesar 1,67 meter dan sumur air bersih III sebesar 1,62 meter. Jadi, kedalaman muka air tanah rata-rata sebesar 1,65 meter.

\section{Luas Bidang Tadah}

Luas area Sekolah Dasar Negeri 1 Pulo Ie adalah sekitar $1500 \mathrm{~m}^{2}$. Dengan dengan riancian bangunan gedung A seluas $161 \mathrm{~m}^{2}$, bangunan gedung B luas $161 \mathrm{~m}^{2}$, gedung $\mathrm{C}$ seluas $105 \mathrm{~m}^{2}$, bangunan gedung $\mathrm{D} 70 \mathrm{~m}^{2}$.

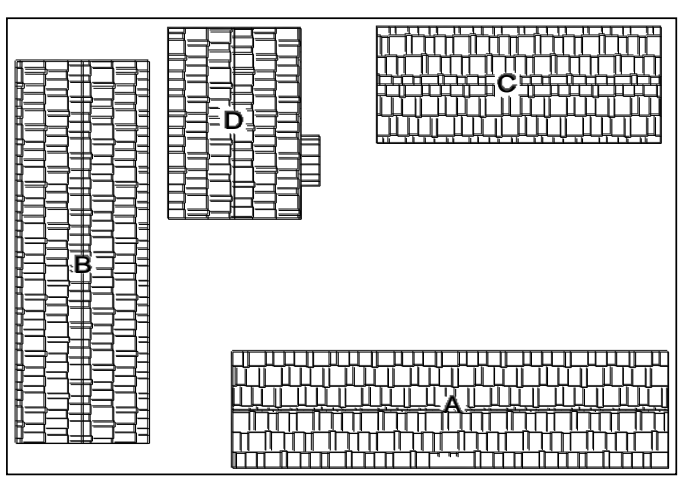

Gambar 1. Sket Lokasi Penelitian 
Luas bidang tadah $\left(\mathrm{A}_{\text {tadah }}\right)$ :

$$
\begin{aligned}
& K D B=\frac{161+161+105+70}{1500} \times 100=33,13 \% \\
& A_{\text {tadah }}=33,13 \% \times 1500=497 \mathrm{~m}^{2}
\end{aligned}
$$

\section{Koefisien Permeabilitas Tanah}

Penentuan harga koefisien permeabilitas (K) suatu sampel tanah pada penelitian didapat dari pengujian falling head permeability. Pengujian permeabilitas tanah menggunakan dua sampel tanah yang berbeda di lokasi studi.

Tabel 2. Hasil pengujian permeabilitas tanah

\begin{tabular}{cccc}
\hline No & $\begin{array}{c}\text { Panjang } \\
\text { Sampel }(\mathrm{cm})\end{array}$ & $\begin{array}{c}\text { Waktu }(\mathrm{t}) \\
(\text { detik})\end{array}$ & $\begin{array}{c}\text { Permeability }(\mathrm{K}) \\
(\mathrm{cm} / \text { det})\end{array}$ \\
\hline 1 & 9,00 & 3600 & 0,01080 \\
2 & 10,00 & 3600 & 0,00865 \\
\hline & & Rata-rata & 0,009725 \\
\hline
\end{tabular}

\section{Nilai Koefisien Limpasan}

Nilai koefisien limpasan (C) didapatkan dari tabel koefisien limpasan permukaan (Runoff Coefisien) berdasarkan jenis penutup lahan dilokasi studi. Maka, ditetapkan nilai koefisien atap sebesar 0,75 .

\section{Analisis Hidrologi}

Analisis Hidrologi sesuai dengan Peraturan Menteri Pekerjaan Umum Nomor 11/PRT/M/2014 dan SNI Nomor 03-2453-2002, dalam perencanaan sumur resapan menggunakan data curah hujan harian rata-rata selama 10 tahun terakhir. Curah hujan harian dapat dilihat pada Tabel 3.

$R=\frac{(362,54)}{10}=36,25 \mathrm{~mm} / \mathrm{hari}$

Jadi, curah hujan rata-rata harian $36,25 \mathrm{~mm} /$ hari $\approx 36,25$ liter/m2/hari

Perhitungan Debit Andil Banjir

$V_{a b}=0,855 \cdot 0,75 \cdot 497 \cdot 36,25$

$V_{a b}=11553$ liter $\approx 11,552 \mathrm{~m}^{3}$

Tabel 3. Curah hujan harian rata-rata

\begin{tabular}{cc}
\hline TAHUN & $\begin{array}{c}\text { Curah Hujan Harian Rata-Rata } \\
(\mathbf{m m}) \text { Maksimum }\end{array}$ \\
\hline 2007 & 31,78 \\
2008 & 33,51 \\
2009 & 28,30 \\
2010 & 44,11 \\
2011 & 43,01 \\
2012 & 25,45 \\
2013 & 43,90 \\
2014 & 39,02 \\
2015 & 32,84 \\
2016 & 40,62 \\
\hline Total & $\mathbf{3 6 2 , 5 4}$ \\
\hline
\end{tabular}

\section{Analisis Sumur Resapan}

1) Rencana Dimensi Sumur Resapan

Adapun sumur resapan yang direncanakan adalah sumur resapan tipe II dengan dinding bata merah yang dapat diterapkan untuk semua jenis tanah. Rencana sumur resapan ditetapkan sumur berpenampang segiempat dengan dimensi sumur resapan sebagai berikut:

- Lebar alas sumur $(\mathrm{L}) \quad=1,20 \mathrm{~m}$

- Panjang alas sumur $(\mathrm{P})=1,20 \mathrm{~m}$

- Kedalaman sumur $(\mathrm{H}) \quad=1,60 \mathrm{~m}$

- Luas alas sumur $\left(\mathrm{A}_{\mathrm{h}}\right)=\mathrm{P} . \mathrm{L}\left(\mathrm{m}^{2}\right)=1,20 \mathrm{mx}$ $1,20 \mathrm{~m}=1,44 \mathrm{~m}^{2}$

- Luas dinding sumur $\left(\mathrm{A}_{\mathrm{v}}\right)=4 . \mathrm{H} . \mathrm{L}\left(\mathrm{m}^{2}\right)=4 \mathrm{x}$ $1,60 \mathrm{~m} \times 1,20 \mathrm{~m}=7,68 \mathrm{~m}^{2}$

- $\mathrm{A}_{\text {total }}=\mathrm{A}_{\mathrm{h}}+\mathrm{A}_{\mathrm{v}}=1,44+7,68=9,12 \mathrm{~m}^{2}$

- $\mathrm{K}$ tanah lempung berpasir $=0,00972 \mathrm{~cm} / \mathrm{det}$ $\approx 8,40 \mathrm{~m} / \mathrm{hari} \approx 8,40 \mathrm{~m}^{3} / \mathrm{m}^{2} /$ hari.

$\mathrm{K}_{\text {vertikal }}\left(\mathrm{k}_{\mathrm{v}}\right)$, untuk dinding tidak kedap air (sumur tipe II), $\mathrm{K}_{\mathrm{h}}=2 \mathrm{k}_{\mathrm{v}}=16,8 \mathrm{~m} / \mathrm{hari}$. 
- Untuk dinding tidak kedap air digunakan

$\mathrm{K}_{\text {rata-rata }}$ :

$$
\mathrm{K}_{\text {rata }}=\frac{8,40 \cdot 1,44+16,8.7,68}{9,12}=15,47 \mathrm{~m} / \text { hari }
$$

2) Jumlah Sumur Resapan

Perhitungan volume air yang meresap digunakan untuk mengetahui banyaknya air yang meresap ke tanah melalui sumur resapan.

$$
V_{r s p}=\frac{0,41}{24} \cdot 9,12 \cdot 15,47=2,41 \mathrm{~m}^{3}
$$

3) Volume Penampungan (Storasi) Air Hujan

$$
V_{\text {storasi }}=11,552-2,41=9,142 \mathrm{~m}^{3}
$$

4) Penentuan Jumlah Sumur Resapan

Dalam penentuan jumlah sumur resapan air hujan terlebih dahulu menghitung $\mathrm{H}_{\text {total }}$.

$$
\begin{aligned}
H_{\text {total }} & =\frac{9,142}{1,44}=6,35 \text { meter } \\
n & =\frac{6,35}{1,60}=4,41 \text { unit }
\end{aligned}
$$

Berdasarkan hasil perhitungan maka, pada Sekolah Dasar Negeri 1 Pulo Ie, dibutuhkan 5 unit sumur resapan agar dapat menampung banjir genangan air hujan. Dimensi sumur resapan penampang segiempat dengan lebar 1,20 meter dan kedalaman 1,60 meter.

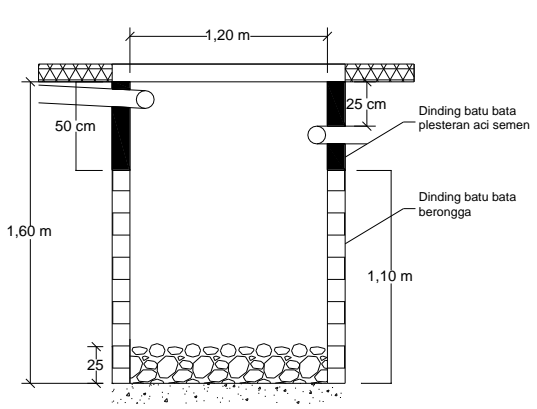

Gambar 2. Sumur Resapan

\section{Penempatan sumur resapan}

Penempatan sumur resapan tehadap bangunan yang direncanakan memenuhi persyaratan Peraturan Menteri Pekerjaan Umum Nomor 11/PRT/M/2014.

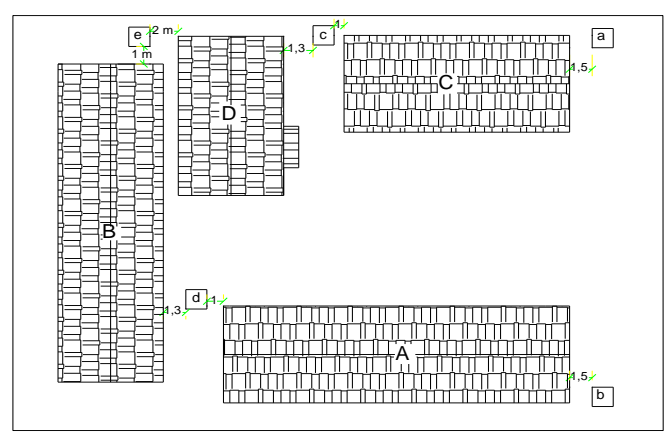

Gambar 3. Penempatan Sumur Resapan

\section{Spesifikasi Sumur Resapan}

Untuk merencanakan sumur resapan yang baik ada beberapa spesifikasi yang direncanakan, yaitu:

- Penutup sumur resapan dibuat penutup dari beton bertulang tebal $12 \mathrm{~cm}$.

- Dinding sumur resapan, menggunakan batu bata merah. Pada dinding kedalaman $0,50-1,10$ meter susunan batu bata diberi rongga agar dapat lebih cepat meresap ke dalam tanah.

- Saluran sumur resapan, konstruksi sumur resapan dilengkapi dengan talang, saluran masuk dan pembuang berbahan pipa PVC diameter $110 \mathrm{~mm}$. 


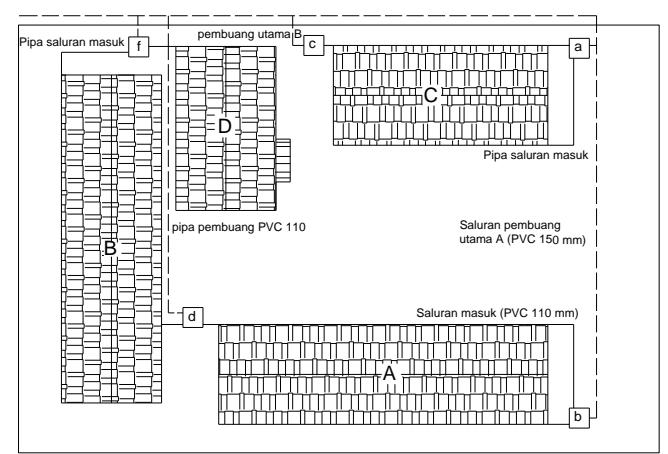

Gambar 4. Penempatan Sumur Resapan

\section{KESIMPULAN}

1. Pengujian falling head permeability, mengindikasikan bahwa kondisi tanah pada lokasi penelitian dikategorikan jenis tanah lempung berpasir dengan nilai koefisien permeabilitas tanah sebesar 0,009725 $\mathrm{cm} /$ detik atau $8,40 \mathrm{~m} /$ hari.

2. Total keseluruhan volume banjir dilokasi Sekolah Dasar Negeri 1 Pulo Ie Kecamatan Kuala sebesar $23,986 \mathrm{~m}^{3}$.

3. Pada kawasan Sekolah Dasar Negeri 1 Pulo Ie diperlukan sumur resapan dengan dimensi yaitu, kedalaman 1,60 meter dengan lebar 1,20 meter.

4. Jumlah sumur resapan yang dibutuhkan adalah sebanyak 5 unit sumur resapan.

\section{DAFTAR PUSTAKA}

Braja, M. Das. (1988). Mekanika Tanah (Prinsip-prinsip Dalam Rekayasa Geoteknis). Jakarta.

Kusnaedi. (2011). Sumur Resapan Untuk Permukiman Perkotaan dan Pedesaan. Jakarta.

Suripin. (2003). Sistem Drainase Perkotaan yang Berkelanjutan, Andi Offset, Yogyakarta.

Soewarno. (1995). Hidrologi Aplikasi Metode Statistik untuk Analisa Data. Bandung: Nova.

Peraturan Menteri Pekerjaan Umum Nomor 11 Tahun 2014. Tentang Pengelolaan Air Hujan pada Bangunan Gedung dan Persilnya. Jakarta.
- How to cite this paper :

Meliyana, M., Syahputra, I., Zain, H., \& Zal, A. (2018). Analisis Kebutuhan Sumur Resapan Sebagai Salah Satu Upaya Dalam Mereduksi Banjir Genangan. Jurnal Teknik Sipil Unaya, 4(2), 6370. 